Pesq. Vet. Bras. 29(2):150-152, fevereiro 2009

\title{
Soroprevalência da infecção por Trypanosoma cruzi em cães de uma área rural do Estado de Mato Grosso do Sul ${ }^{1}$
}

\author{
Alda I. Souza ${ }^{2}$, Tricia M.F.S. Oliveira ${ }^{3}$, Rosangela Z. Machado ${ }^{4}$ e \\ Aparecido A. Camacho ${ }^{5}$
}

\begin{abstract}
Souza A.I., Oliveira T.M.F.S., Machado R.Z. \& Camacho A.A. 2009. [Seroprevalence of infection by Trypanosoma cruzi in dogs in a rural area of Mato Grosso do Sul, Brazil.] Soroprevalência da infecção por Trypanosoma cruzi em cães de uma área rural do Estado de Mato Grosso do Sul. Pesquisa Veterinária Brasileira 29(2):150-152. Curso de Medicina Veterinária, Universidade para o Desenvolvimento do Estado e da Região do Pantanal, Rua Alexandre Herculano 1400, Jardim Veraneio, Campo Grande, MS 79037-280, Brazil. E-mail: aldaizabel@ hotmail.com

Chagas disease is an anthropozoonosis caused by Trypanosoma cruzi and dogs are considered to be one of the main reservoirs of the disease in the South America. This study evaluates the occurrence of the infection caused by $T$. cruzi in dogs from a rural area of Mato Grosso do Sul, Brazil. Indirect immunofluorescence test (IFI) and enzyme-linked immunosorbent assay (ELISA) was used in 75 dogs living in this area. The antibodies were detected in $45.3 \%(n=34)$ and $24.0 \%(n=18)$ with IFI and ELISA, respectively. The actual prevalence of the infection was confirmed as $22.7 \%(n=17)$ by the criterion of positivity in both tests. The results confirm T. cruzi infection in dogs in the region.
\end{abstract}

INDEX TERMS: Diseases of dogs, Trypanosoma cruzi, seroprevalence, Mato Grosso do Sul.

RESUMO.- Doença de Chagas é uma antropozoonose causada por Trypanosoma cruzi que tem os cães como importante reservatório da doença na América do Sul. Este trabalho teve como objetivo avaliar a ocorrência da infecção natural pelo $T$. cruzi em cães de uma área rural do estado de Mato Grosso do Sul, Brasil. Foram utilizados os testes de imunofluorescência indireta (IFI) e ensaio imunossorvente ligado a enzima (ELISA) em 75 cães residentes na área. Foram detectados anticorpos em $45,3 \%$ $(n=34)$ e $24,0 \%(n=18)$ nos testes de IFI e ELISA, respectivamente. A real prevalência da infecção foi confirmada

\footnotetext{
${ }^{1}$ Recebido em 28 de julho de 2008.

Aceito para publicação em 25 de janeiro de 2009

${ }^{2}$ Curso de Medicina Veterinária, Universidade para o Desenvolvimento do Estado e da Região do Pantanal (Uniderp), Rua Alexandre Herculano 1400, Jardim Veraneio, Campo Grande, MS 79037-280, Brasil. "Autor para correspondência: aldaizabel@ hotmail.com

${ }^{3}$ Programa de Pós-Graduação em Medicina Veterinária, Faculdade de Ciências Agrárias e Veterinárias (FCAV), Universidade do Estado de São Paulo (Unesp), Campus de Jaboticabal, Via de Acesso Prof. Paulo Donato Castellane s/n, Jaboticabal, SP 14884-900, Brasil.

${ }^{4}$ Departamento de Patologia Animal, FCAV, Unesp, Jaboticabal, SP.

${ }^{5}$ Departamento de Clínica Médica, FCAV, Unesp, Jaboticabal, SP.
}

como $22,7 \%(n=17)$ pelo critério de positividade em ambos os testes. Os resultados obtidos confirmam a infecção chagásica nos cães dessa região.

TERMOS DE INDEXAÇÃO: Doenças de cães, Trypanosoma cruzi, soroprevalencia, Mato Grosso do Sul.

\section{INTRODUÇÃO}

Doença de Chagas é causada por Trypanosoma cruzi, um hemoflagelado transmitido principalmente por insetos vetores que se mantém na natureza parasitando grande quantidade de espécies de mamíferos, inclusive o homem (WHO 2002). Os cães são considerados importantes reservatórios de $T$. cruzi e têm um relevante papel na manutenção e interação entre o ciclo doméstico e silvestre da doença (Montenegro et al. 2002, Crisante et al. 2006). Portanto, considerando que o estudo nessa espécie é importante para determinar a presença do tripanosomatideo e o risco de seres humanos contraírem a doença (Cohen \& Gürtler 2001, Reithinger et al. 2005), objetivou-se avaliar a reatividade de anticorpos anti-Trypanosoma cruzi em cães de uma área rural no Mato Grosso do Sul, onde casos humanos autóctones da doença de Chagas foram previamente relatados (Borges-Pereira et al. 2001, Pompilio et al. 2005). 


\section{MATERIAL E MÉTODOS}

Foram colhidas amostras de sangue de 75 cães (57 machos e 18 fêmeas), provenientes de uma área rural localizada no município de Jaraguari, $35 \mathrm{~km}$ ao norte da capital de Mato Grosso do Sul. As amostras, após centrifugação para obtenção do soro, foram armazenadas em tubos plásticos do tipo Eppendorf (Eppendorf do Brasil, São Paulo, Brasil) e acondicionadas a $20^{\circ} \mathrm{C}$ até o momento da realização das provas. Foram utilizados os testes de imunofluorescência indireta (IFI) e de ensaio imunossorvente ligado a enzima (ELISA).

A pesquisa de anticorpos anti-Trypanosoma cruzi por meio do ELISA utilizou um extrato total de formas epimastigotas, conforme descrito previamente (Umezawa 1996), e foi realizada no Laboratório de Investigação Médica de Protozoologia, da Faculdade de Medicina da Universidade de São Paulo, São Paulo. Foram consideradas sororeagentes as amostras que apresentaram uma densidade óptica (DO) $>0,25$. A determinação da linha de corte (cut-off) foi estabelecida a partir da média de DO das amostras de 35 cães, sabidamente negativos, acrescida de três desvios-padrão.

A pesquisa de anticorpos anti- $T$. cruzi por meio da IFI foi realizada no Laboratório de Imunoparasitologia do Departamento de Patologia, da Universidade Estadual Paulista (Unesp), Campus de Jaboticabal, São Paulo. A fim de avaliar a possível ocorrência de reação cruzada para com anticorpos anti-Leishmania chagasi foi também realizada IFI, conforme descrito previamente (Oliveira 2004). Em ambos os testes, foram considerados positivas as amostras reagentes na diluição e"1:40.

Para a confirmação da infecção, levaram-se em consideração os critérios preconizados pela Organização Mundial de Saúde (WHO 2002) para o diagnóstico da infecção humana, no qual são consideradas positivas apenas as amostras reagentes, simultaneamente, nos dois testes.

Com o objetivo de confirmar a presença de T. cruzi e de Leishmania spp. na área, quatro cães que atenderam ao critério de positividade para infecção chagásica e não apresentaram anticorpos anti-Leishmania foram submetidos ao xenodiagnóstico clássico, utilizando 30 ninfas de Triatoma infestans e 30 ninfas de $T$. sordida, e ao exame parasitológico direto para observação de formas amastigotas de Leishmania sp. nos linfonodos. Esses exames foram realizados de acordo com técnicas previamente estabelecidas (Rey 2003, MS 2006). Dos 10 cães sororeagentes tanto para T. cruziquanto para Leishmania, dois foram submetidos ao xenodiagnóstico clássico e seis foram submetidos ao exame parasitológico direto.

\section{RESULTADOS E DISCUSSÃO}

Das amostras estudadas $(n=75)$, foram sororeagentes $45,3 \%(n=34)$ na IFI e $24,0 \%(n=18)$ no ELISA. Com a utilização do critério preconizado pela Organização Mundial de Saúde (WHO 2002), 22,7\% ( $n=17)$ das amostras foram consideradas positivas. Esses 17 casos demonstraram títulos que variaram de 80 a 2.560 na IFI e DO entre 0.22 e 1.38 no ELISA (Quadro 1). Acreditamos que esses resultados possam representar a real prevalência da infecção na área.

A soroprevalência da infecção por Trypanosoma cruzi neste estudo foi muito superior a observada em outra área do Estado (Silva 1979), que detectou apenas 3\% de positividade através da técnica de IFI, aproxima-se da observada na Argentina (Lauricella et al. 1989) e na Costa Rica (Montenegro et al. 2002) e confirma a infecção chagásica nos cães de Mato Grosso do Sul.

A variação no número de cães infectados dentro do mesmo estado (22,7\% versus $3 \%$ ) talvez possa ser explicada pela dependência de características epidemiológicas particulares de cada área, dentre elas, as condições sanitárias e das habitações, a densidade de triatomíneos e a presença de animais sinatrópicos e humanos infectados na área (Barr et al. 1991).

O uso de formas epimastigotas como antígeno apresenta reatividade cruzada principalmente nas amostras de soros de indivíduos infectados com Leishmania spp. (Umezawa \& Silveira 1999). Portanto, esta alta prevalência de cães positivos pode ser causada pela reatividade cruzada com cães infectados com Leishmania spp. Vários autores (Malchiodi et al. 1994, Umezawa \& Silveira 1999) alertam que os métodos sorológicos são considerados importantes ferramentas no diagnóstico da infecção chagásica, uma vez que os níveis de anticorpos permanecem por décadas, porém, em humanos, a reação cruzada com a leishmaniose em áreas onde as doenças se sobrepõem prejudica a especificidade dos testes convencionais. Em um estudo utilizando cães (Lauricella et al. 1989), foi demonstrada especificidade de $96,2 \%$ com ELISA e o teste foi recomendado para a triagem nessa espécie, contudo, é importante ressaltar que tal estudo foi conduzido em área livre de leishmaniose canina.

Dos cães incluídos no critério de infecção para T. cruzi, estabelecido neste estudo, 58,8\% (10/17) também apresentaram reatividade na IFI para Leishmania chagasi (Quadro 1) e embora nenhum cão revelasse sinais clínicos da leishmaniose, a alta probabilidade de uma reatividade cruzada ou a presença concomitante das duas doenças deve ser levada em consideração (Umezawa \& Silveira 1999).

Dois cães foram positivos no xenodiagnóstico para $T$. cruzi e três foram positivos para Leishmania sp. e embora confirmem a existência dos agentes na área, deve-se levar em conta que a inviabilidade para a realização do xenodiagnóstico em todos os cães deste estudo, associada a baixa sensibilidade dos testes parasitológicos não

\section{Quadro 1. Número e positividade nos testes sorológicos usados para diagnóstico de doença de Chagas (ELISA, IFI-Ch) e leishmaniose visceral canina (IFI-leish)}

\begin{tabular}{|c|c|c|c|}
\hline \multirow[t]{3}{*}{$\mathrm{n}$} & \multicolumn{3}{|c|}{ Testes sorológicos } \\
\hline & \multicolumn{2}{|c|}{ Trypanosoma cruzi } & \multirow{2}{*}{$\begin{array}{c}\text { Leishmania chagasi } \\
\text { IFI-leish }\end{array}$} \\
\hline & IFI-Ch & ELISA & \\
\hline 10 & 10 & 10 & 10 \\
\hline 07 & 7 & 7 & 0 \\
\hline 17 & 17 & 0 & 0 \\
\hline 01 & 0 & 1 & 1 \\
\hline 01 & 0 & 0 & 1 \\
\hline 39 & 0 & 0 & 0 \\
\hline 75 & $34(45,3 \%)$ & $18(24,0 \%)$ & $12(16,0 \%)$ \\
\hline
\end{tabular}


permitiram descartar dupla infecção, mesmo nos cães que reagiram sorologicamente para os dois antígenos e reafirma a dificuldade na diferenciação entre infecção por $T$. cruzi e Leishmania spp. em cães assintomáticos utilizando técnicas convencionais de diagnóstico.

Não se observou nenhuma diferença estatisticamente significativa (c2: 0,003, $\mathrm{P}<0,05)$ entre machos e fêmeas sugerindo uma similar susceptibilidade à infecção, pois dos 17 cães considerados reagentes, 22,8\% (13/57) eram machos e 22,2\% (4/18) eram fêmeas.

Não foi possível analisar estatisticamente a correlação entre a idade e a ocorrência de infecção devido ao desconhecimento da maioria dos proprietários e a subjetividade do exame físico e da arcada dentária para a obtenção dessa informação, tendo em vista serem cães procedentes de área rural.

\section{CONCLUSÕES}

Por ser esta a primeira avaliação sorológica realizada em cães nessa região do Estado de Mato Grosso do Sul, considerando a confirmação da presença do agente e os altos índices de soropositividade e valendo-se da afirmativa de que o cão é um sentinela para infecção chagásica em seres humanos (WHO 2002, Crisante et al. 2006), ressaltase a necessidade da utilização de testes diagnósticos mais específicos para estudos na área, a fim de esclarecer a real prevalência da infecção, estabelecer a epidemiologia e identificar o papel do cão na transmissão da doença.

Agradecimentos.- Os autores agradecem à Dra . Eufrosina Umezawa e seu grupo, do Laboratório de Investigação Médica de Protozoologia da Faculdade de Medicina da Universidade de São Paulo, pela realização do ELISA.

\section{REFERÊNCIAS}

Barr S.C., Dennis V.A. \& Klei T.R. 1991. Serologic and blood culture survey of Trypanosoma cruzi infection in four canine population of southern Louisiana. Am. J. Vet. Res. 52:570-573.

Borges-Pereira J., Zauza P.L., Galhardo M.C., Nogueira J.S., Pereira G.R.O.L. \& Cunha R.V. 2001. Doença de Chagas na população urbana do distrito sanitário de Rio Verde, Mato Grosso do Sul, Brasil. Revta Soc. Bras. Med. Trop. 34:459-466.
Cohen J.E. \& Gürtler R.E. 2001. Modeling household transmission of American Trypanosomiasis. Science 293:694-698.

Crisante G., Rojas A., Teixeira M.M.G. \& Añez N. 2006. Infected dogs as a risk factor in the transmission of human Trypanosoma cruzi infection in western Venezuela. Acta Trop. 98:247-254.

Lauricella M.A., Sinagra A.J., Paulone I., Riarte A.R. \& Segura E.I. 1989. Natural Trypanosoma cruzi infection in dogs of endemic areas of Argentine Republic. Revta Inst. Med. Trop. São Paulo 31:63-70.

Malchiodi E.L., Chiaramonte M.G., Taranto N.J., Zwirner N.W. \& Margni R.A. 1994. Cross-reactivity studies and differential serodiagnosis of human infections caused by Trypanosoma cruzi and Leishmania spp.: the use of immunoblotting and ELISA with a purifed antigen (Ag 163B6). Clin. Exp. Immunol. 97:417-423.

MS 2006. Manual de Vigilância e Controle da Leishmaniose Visceral. Departamento de Vigilância Epidemiológica, Secretaria de Vigilância, Ministério da Saúde, Brasília.

Montenegro V.M., Jiménez M., Pinto Dias J.C. \& Zeledón R. 2002. Chagas disease in dogs from endemic areas of Costa Rica. Mem. Inst. Oswaldo Cruz 97:491-494.

Oliveira T.M.F.S. 2004. Detecção de anticorpos anti-Leishmania chagasi, em soros de cães do Município de Jaboticabal, área não-endêmica para a doença. Dissertação de Mestrado em Patologia Animal, Faculdade de Ciências Agrárias e Veterinária, Universidade Estadual Paulista, Jaboticabal, SP. 45p.

Pompilio M.A., Dorval M.E., Cunha R.V., Britto C. \& Borges-Pereira J. 2005. Clinical and parasitological aspects of Chagas' disease in Mato Grosso do Sul State. Revta Soc. Bras. Med. Trop. 38:473-478.

Reithinger R., Ceballos L., Stariolo R., Davies C. \& Gürtler R.E. 2005. Chagas disease control: Deltamethrin-treated collar reduce Triatoma infestans feeding success on dog. Trans. R. Soc. Trop. Med. Hyg. 99:502-508.

Rey L. 2003. Protozoários parasitos do homem, p.115-339. In: (Ed.), Parasitologia. Guanabara Koogan, Rio de Janeiro. 379p.

Silva R.P. 1979. Estudo sobre Trypanosoma (Schizotrypanum) cruzi Chagas, 1909 em área de Mato Grosso do Sul: casos humanos, reservatórios e transmissores. Tese de Doutorado, Instituto de Biociências, USP, São Paulo. 83p.

Umezawa E.S. \& Silveira J.F. 1999. Serological diagnosis of Chagas disease with purified and defined Trypanosoma cruzi antigens. Mem. Inst. Oswaldo Cruz 94:285-288.

Umezawa E.S., Shikanai-Yasuda M.A. \& Stolf A.M.S. 1996. Changes in isotype composition and antigen recognition of anti-T.cruzi antibodies from acute to chronic Chagas disease. J. Clin. Lab. Anal. 10:407-413.

WHO 2002. Control of Chagas disease. Second Report of the WHO Expert Committee, World Health Organization, Brasilia. 109p. 